\title{
Barriers to Parental Involvement for Diverse Families in Early Childhood Education
}

\author{
Muhammed Öztürk \\ Aksaray University, Aksaray, 68100,Turkey
}

\section{Doi:10.5901/jesr.2013.v3n7p13}

\begin{abstract}
Recently, parental involvement in early childhood education has become increasingly interested by researchers. The study of parental involvement for families that are culturally diverse has become an important aspect of education. The review's purpose is to deepen understanding of barriers that inhibit parental involvement for parents who come from diverse culture and race. There are two basıc barriers that the majority of immigrant parents face, which are limited English proficiency and cultural differences. These barriers show that early childhood teachers have significant responsibilities to overcome these barriers by working collaboratively with families.
\end{abstract}

Keywords: Parent involvement, immigrant, diverse culture, race;

\section{Introduction}

A large amount of research indicates that parental involvement generally has a significant effect on children's academic success (Jeynes, 2011). The study of parental involvement for families that are culturally diverse has become an important aspect of education. According to the U.S Census Bureau data (U.S. Census Bureau, 2009), 38 million of the U.S. population is foreign born with 22 million being foreign born and non-U.S citizens. This means that approximately $12 \%$ of the United States population is immigrant. These large immigrant populations have necessitated research studies about parental involvement for culturally and racially diverse families. These studies have examined fundamental needs of these families, rate of parental involvement, and barriers that prevent parental involvement. The goal of this study is to examine what are the most common barriers that prevent parental involvement for families that come from a different culture, race, and ethnicity.

\section{Parental Involvement}

A wide range of research in the United States and other countries supports the view that parental involvement generally has a positive effect on children's academic achievement (Holloway, Yamamoto, Suzuki, \& Mindnich, 2008). Children's experiences in kindergarten and first grade lay a foundation, and parents have a key role to determine their children's experiences (Turney \& Kao, 2009). Parental involvement helps students succeed in school and build strong parentschool partnerships. Research indicates parent's involvement in their children's education is beneficial to students and parents as well as to the educator (Sohn \& Wang, 2006). Students can increase motivation and achievement in education and improve self confidence. Parents can understand school curriculum and activities more profoundly and also can get opportunities to work closely with educators. Teachers can take advantage from parental involvement by learning family perspectives (Sohn \& Wang, 2006). Many experimental studies show strong relationships between higher student achievement and parental involvement (Wong \& Hughes, 2006).

There is a positive link between parental involvement and student competence, grades and achievement scores (Shah, 2009). According to a recent national survey, $95 \%$ of public school parents indicated that it is very important to encourage families to take a more active role in educating their children (Bridgemohan, Van Wyk, \& Van Staden, 2005). In addition, parental involvement keeps parents socially active, such as knowing other parents, teachers, and administrators (Turney \& Kao, 2009). Moreover, where parental involvement programs are established in early childhood programs, the benefits are apparent throughout the child's school career (Bridgemohan et al., 2005). Looking from policy perspective, parental involvement is important because one of the goals of the No Child Left Behind Act of 2001 is to increase parental involvement in elementary school (Turney \& Kao, 2009). 


\section{Parental involvement for culturally diverse families}

It is not an easy to task arrange programs and project parental involvement, especially when parents come from a different culture, race and language (Chen, Kyle, \& McIntyre, 2008). Joshi Eberly and Konzal, (2005) indicates that it is very difficult building strong and respectful relationships between families and teachers who share similar cultural backgrounds and language. Such communication and relations between parents and teachers who come from different backgrounds is even more difficult (Joshi et al., 2005). When parents do not share a common culture with teachers, it is more difficult to establish shared understanding and to build trust (Wong \& Hughes, 2006).

According to Wong and Hughes (2006) that much educational research has investigated why some parents get involved in their children's education and others do not. Much of this research has investigated the role of race and ethnicity in parental involvement, with varying findings.

One of the greatest misconceptions is that parents of immigrant students have no interest in their children's education (Varela, 2008). For numerous reasons, researchers have found that parents of racially, ethnically, and linguistically diverse students often fail to participate in school activities (Shah, 2009). Immigrant parental involvement has been investigated profoundly by researchers; the reasons why they do not get involved in their child's education and school activity are diverse. To examine them, Turney and Kao (2009) studied early childhood education by examining immigrant barriers to parental involvement and parents' involvement in their children's education. They used data from the Early Childhood Longitudinal Study- Kindergarten Cohort, a nationally representative sample of children in kindergarten from 1998- 1999. In this study, they presented multivariate analyses that showcase barriers that prevent parents from getting in touch with their children's teachers and schools. They focused on the barriers faced by immigrant groups and found significant barriers related to involvement in their children's kindergarten classrooms. According to their study, all minority immigrant groups reported facing more barriers related to involvement including lack of English language ability, not feeling welcome at the school, and cultural differences.

\section{Barriers}

When parents and teachers come from different backgrounds, there are a few barriers that prevent parent-school relationships (Joshi et al., 2005). Joshi et al. (2005) argue that the following additional barriers that prevent parents and teachers from communicating openly and honestly are a "lack of understanding of the home school partnerships, lack of understanding of the school system; lack of confidence, work interference, negative past experiences with schools, and insensitivity or hostility on the part of the school personnel" (p.3). According to Denessen, Bakker, and Gierveld's (2007) study that was carried out in four Dutch elementary schools, some specific problems regarding ethnic minority parents are the lacking of language skills to communicate with the school; holding the school fully responsible for their child's education; and not being interested in school matters. Ethnic minority parents thus seemed to be less involved at their child's school than native Dutch parents. In this sense, Shartrand, Weiss, Kreider, and Lopez (1997) state that the first reason for lower levels of parental involvement of minority parents is that these parents lack the required cultural resources to become involved. The second reason lies in the cultural incongruence between schools and minority families (Denessen et al., 2007).

\subsection{Language}

The increasing number of immigrant students from non-English speaking countries makes school in the United States linguistically diverse. According to U.S Census report (U.S Census Bureau, 2009), 12.54\% of the population in 2009 was foreign-born; $19.7 \%$ of the population spoke language other than English at home, and $8.6 \%$ of the population spoke English less than very well (Chen, Kyle, \& Mclntyre, 2008). Many parents do not have the ability to speak English and they try to help their child with homework, but their limited English skills often prevent them (Colombo, 2006). This information also shows that there is a large amount of students and parents who speak English as a second language. One of the most common barriers that prevents effective partnerships between teachers and parents is language. Language problems as the most important reason for low levels of ethnic minority parental involvement (Denessen et al., 2007). According to a study by Sohn and Wang (2006) regarding six Korean speaking immigrant families, the language barrier has a significant effect on immigrant's parental involvement. All parents emphasized difficulties communicating with teachers in English (Sohn \& Wang, 2006). Limited knowledge about educational notions is another difficulty for communication for parents. Although they really want to communicate with teachers and school administrators, they felt 
frustrated when the teacher and another school staff often did not understand their English (Sohn \& Wang, 2006). For these reasons, those Korean parents do not prefer to contact the teacher directly, they prefer other routes such as e-mail and school letters because they are able to understand written English better than spoken English. Additionally, parents who do not speak English at home may be less comfortable at their children's school. If a parent's primary language is not English, they generally report problems such as meeting times are unsuitable, they do not feel welcome in the school, and the teacher or school administrator speaks only English (Turney \& Kao, 2009).

\subsection{Culture}

The second barrier to parental involvement is cultural barriers that include different lifestyles, values, culture, and experiences between teacher and parents (Morris \& Taylor, 1998). Cultural differences make parental involvement more difficult for teachers and school administrators (Denessen et al., 2007). Morris and Taylor (1998) argue that parents sometimes reveal barriers to effective teacher-parent communication. For example, some parents may hesitate to ask teachers about some issues because they fear that they might negatively affect teachers' behaviors toward their children. According to Ariza (2002), facing different cultural groups at the school makes parents uncomfortable. One of the important reasons why teachers avoid communication with parents from different culture is that they do not have any idea about cultural differences in nonverbal communications. For example, looking each other in the eyes while conversating could be considered disrespectful for other cultures (Denessen et al., 2007). Thus, not having any idea about other's cultures, lifestyles, and values prevent relationships between people who come from different cultures. All these reasons affect direct parental involvement and indirect student achievement negatively.

\section{Role of Teacher}

Research studies show that there are many ways for immigrants to get involved in their children's education. An important way to help immigrant parents and their children succeed is to first develop a community of teachers who understand the value of multiculturalism and are trained to face the challenges and rewards inherent in teaching immigrant students (Varela, 2008). A lot of teachers have not received enough training to engage different groups of parents. Varela (2008) states that immigrant parents need two elements in order to become a vital part of the school setting. First, a community of "Teachers as Learners" was created to challenge misconceptions about immigrant groups. Second, the school community had to openly embrace the needs of immigrant parents by involving them in their child's educational process without consideration of any sociocultural, socioeconomic, and sociolinguistic differences. A teacher training program might be needed for the improvement of teachers' competence to communicate with immigrant parents (Denessen et al., 2007).

Teachers and administrators can improve their skills and knowledge by taking professional development programs for parental involvement from school psychologists. (Wong \& Hughes, 2006). Thus, it is important for school psychologists to work at the school system level to implement broadbased, empirically supported parental involvement practices (Wong \& Hughes, 2006). Shartrand et al. (1997) provide a framework of content areas for teacher preparation. These content areas contain basic family involvement and knowledge, home-school contact, parental involvement in the learning process, how families assist schools and how schools can assist families. For communication between parents and teachers to be meaningful and responsive, it is necessary to have knowledge about differing cultural frameworks (Wong \&Hughes, 2006).

All studies emphasize that school administrators and supervisors must work closely with teachers to arrange a variety of school activities that address the needs of the community and families, including literacy workshops, ESL classes, open houses that adapt to immigrant parents' work schedules, and classes to teach parents how to help their children with homework. Finally, if a school takes precautions to make immigrant parents feel welcome at the school or to reduce the language, or other barriers, that parents face, children could take a significant advantage (Turney \& Kao, 2009).

Graham-Clay (2005) argues that before the communication, there are three important steps that teachers have to consider. First, communication between teachers and parents starts with a welcome sign when parents first come to school. The second step may be a smile, because meeting parents with smile is influential. The third step is a clean school as this affects parents thoughts about a school. Additionally, Al-Hassan and Gardner (2002) suggest some tactics for educators to get immigrant parents more actively involved are sending welcome notes to the immigrant parents in their language, inviting them to the school, being aware of special cultural and religious holidays, including them on the 
school calendar as classroom celebrations, and making home visits.

\section{Conclusion}

There are two main barriers that the majority of immigrant parents face, which are limited English proficiency and cultural differences. These barriers show that teachers have significant responsibilities to overcome these barriers by working collaboratively with families. Teachers and school administrators should find appropriate ways to contact families that are culturally and linguistically diverse to get them involved. McWilliam, Maxwell, and Sloper (1999) explain advocacy as guiding families to advocate for themselves. In this respect, all barriers, which prevent parental involvement for families that are culturally and linguistically diverse, show that this community needs greater advocacy than other families. For family advocacy, educators and school administrators should arrange activities and the school environment towards the goal of family advocacy for families that are culturally and linguistically diverse. If teachers get in touch with parents who are not from the majority culture and race, educators and school staff will create a school environment that is nonthreatening, a place that nurtures parents and allows all parents to feel comfortable (Ariza, 2002). All parents need support, advocacy, and guidance, no matter their culture or race because all families want their children to be successful at school and they are enthusiastic to participate in their children's school activity.

\section{References}

Al-Hassan, S., \& Gardner, R. (2002). Involving immigrant parents of students with disabilities in the educational process. Teaching Exceptional Children, 34(5), 52- 58.

Ariza, E. N. (2002). Cultural considerations: immigrant parent involvement. Kappa Delta Pi Record, 38(3), 134-137.

Bridgemohan, R., Van Wyk, N., \& Van Staden, C. (2005). Home-School communication in the early childhood development phase. Education, 126(1), 60-77.

Chen, C.-T., Kyle, D. W., \& McIntyre, E. (2008). Helping teachers work effectively with english language learners and their Families. The School Community Journal, 18(1), 7-20.

Colombo, M. W. (2006). Building school partnerships with culturally and linguistically diverse families. Phi Delta Kappan, 88(4), 314-318.

Denessen, E., Bakker, J., \& Gierveld, M. (2007). Multi-Ethnic schools' parental involvement policies and practices. The School Community Journal, 17(2), 27-43.

Graham-Clay, S. (2005). Communicating with Parents: Strategies for Teachers. The SchoolCommunity Journal, 15(1), 117-129.

Holloway, S. D., Yamamoto, Y., Suzuki, S., \& Mindnich, J. D. (2008). Determinants of parental involvement in early schooling: Evidence from Japan. Early Childhood Research \& Practice, 10.

Jeynes, W. H. (2011). Parental Involvement and Academic Success. New York: Routledge.

Joshi, A., Eberly, J., \& Konzal, J. (2005). Dialogue across cultures: Teachers' perceptions about communication with diverse Families. Multicultural Education , 13(2), 11-15.

McWilliam, R. A., Maxwell, K. L., \& Sloper, K. M. (1999). Beyond involvement: are elementary schools ready to be family-centered? The School Psychology Review, 28(3), 378-394.

Morris, V. G., \& Taylor, S. I. (1998). Alleviating barriers to family involvement in education: the role of teacher education. Teaching and Teacher Education,14(2), 219-231. DOI: 10.1016/s0742-051x(97)00037-1

Shah, P. (2009). Motivating Participation: The symbolic effects of latino representation on parent school involvement. Social Science Quarterly, 90(1), 212-230. DOI: 10.1111/j.1540-6237.2009.00612.x

Shartrand, A. M., Weiss, H. B., Kreider, H. M., \& Lopez, M. E. (1997). New Skills for New Schools: Preparing Teachers in Family Involvement. Retrieved fromhttp://www.eric.ed.gov/PDFS/ED414254.pdf

Sohn, S., \& Wang, X. C. (2006). Immigrant parents' involvement in american schools: perspectives from korean mothers. Early Childhood Education Journal, 34(2), 125-132. DOI: 10.1007/s10643-006-0070-6

Turney, K., \& Kao, G. (2009). Barriers to school involvement: Are immigrant parents disadvantaged? The Journal of Educational Research, 102(4), 257-271. DOI: 10.3200/joer.102.4.257-271

U.S. Census Bureau. (2007). Fact sheet: 2009 American community survey, selected characteristics of the native and foreign-born populations. Retrieved April 15, 2011, from http://factfinder.census.gov/servlet/STTable?_bm=y\&-geo_id=01000US\&gr name=ACS 2009 1YR G00 S0501\&-ds name=ACS 2009 1YR G00 \&- lang=en\&-redoLog=falses

Varela, A. (2008). Embrace Multiculturalism to foster parental involvement. The Education Digest, 74(3), 59-60.

Wong, S. W., \& Hughes, J. N. (2006). Ethnicity and language contributions to dimensions of parent involvement. The School Psychology Review, 35(4), 645- 662. 